\title{
OPC UNIFIED ARCHITECTURE DESIGN ASPECTS AND SERVICES IMPLEMENTATION
}

\author{
STOPPER, M. \& KATALINIC, B.
}

Abstract: OPC Unified Architecture is the most recent OPC specification from the OPC Foundation and differs significantly from its predecessors. The OPC Foundation's main goals with this development was to provide a path forward from the original OPC communications model (COM/DCOM) to a current infrastructure model (SOA) and introduce a cross-platform architecture for process control, while enhancing security and providing an information model. By defining abstract services into service sets groups, which are defined by their request and response messages, OPC UA provides this service-oriented architecture (SOA) for industrial applications, starting from factory floor devices and ending with enterprise applications. OPC UA integrates the different aspects of the former OPC specifications into a unified address space accessible with a single set of services. This work gives an overview about some edge design aspects as well as services implementation of OPC UA regarding the underlying SOA-conform architecture.

Authors.

Key words: service oriented architecture, ole for process control, opc unified architecture, industrial web services
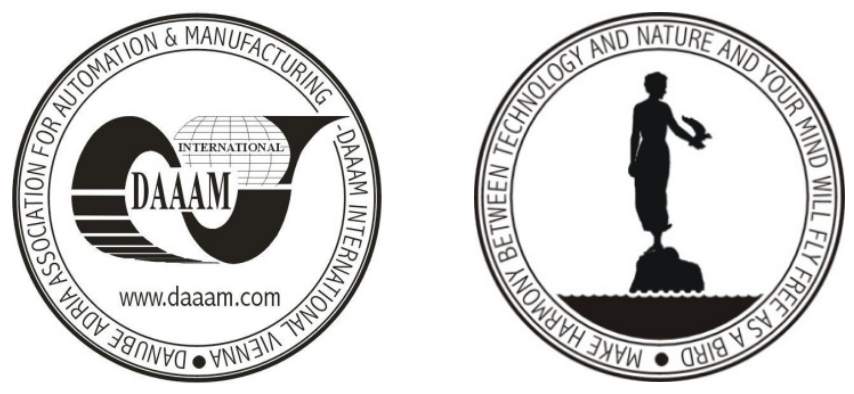

Authors' data: Dr. Sc. Stopper, M[arkus]*; Professor Dr. Dr.mult.h.c. Katalinic, $\mathrm{B}[$ ranko]**; *IMS/Institute of Production Engineering, **Vienna University of Technology, A-1040, Vienna, Austria, markus.stopper@ieee.org, katalinic@ift.tuwien.ac.at

This Publication has to be referred as: Stopper, M[arkus] \& Katalinic, B[ranko] (2008). OPC Unified Architecture Design Aspects and Services Implementation, Chapter 69 in DAAAM International Scientific Book 2008, pp. 855-862, B. Katalinic (Ed.), Published by DAAAM International, ISBN 978-3-901509-66-7, ISSN 17269687, Vienna, Austria

DOI: $10.2507 /$ daaam.scibook.2008.69 